existence of anticomplements was later shown by Moreschi to be simulated by a Bordet-Gengou reaction. Thus, on injection of foreign serum, an antibody is produced; in vitro, this along with the serum fixes complement, the indicator being sensitized red corpuseles added,later, which remain intact. 'The delicacy of this test for determining the species of serum and certain other proteins in amounts of the order of less than $1 \gamma$ exceeds that of the precipitin reaction. The work of Neisser and Sachs on this subject in Ehrlich's laboratory emphasized its practical value, the most outstanding instance of which is the Wassermann reaction.

Theobald Smith directed attention to the observation that guinea pigs which had survived the injection of a mixture of diphtheria toxin and antitoxin from the horse became severely ill and often died when they received a large dose of horse serum at a later date. But animals which had originally received a massive dose of serum alone (to confirm absence of harmful constituents) usually withstood the second dose. Analysis of the "Theobald Smith phenomenon" by Otto in Ehrlich's laboratory and by others showed that this form of supersensitiveness, called anaphylaxis, has as its basis the antibody reaction set up by the original minute dose of foreign serum, and that it is specific and essentially independent of the toxin, although the latter may be an adjuvant. Anaphylaxis can be transforred passively. 'This work played a large part in emphasizing the importance of allergic phenomena in disease.

Ehrlich's 'wet nurse experiment' in mice demonstrated that transmission of antitoxic immunity to the offspring occurs only through their ingesting the milk of an immunized female, which contains the antibody--but in some species there is transplacental transfer. Thus the immunity of the young is passive. There is no hereditary transmission of acquired humoral immunity either from the father or mother.

In 1908 Ehrlich shared with Elie Metchnikoff the Nobel Prize for Medicine "in recognition of his work on Immunity".

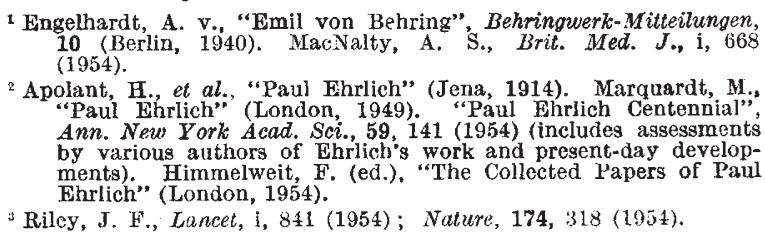

(To be continued)

\title{
EVOLUTION OF THE EARTH
}

A JOINT discussion of the Geological and Royal Astronomical Societies was held in the apartments of the Geological Society at Burlington House on February 2 to consider problems discussed by the late Dr. G. M. Lees in his presidential address to the Geological Society in 1953-"The Evolution of a Shrinking Earth" (Quart. J. Geol. Soc., 109, 217-257; 1953). This address was not primarily concerned with "The Origin of the Earth", the advertised title of the discussion, and only one speaker, Mr. T. Gold, related his remarks to that problem. Unfortunately, many who came to listen - and some to speak - failed to gain a footing in the overcrowded meeting room.

trof. L. Hawkes, in opening the discussion, said that Dr. Lees had challenged some conceptions regarding the earth's crust which are widely held by both geologists and geophysicists ; in particular, his view that there may be no fundamental difference between the basement of the oceans and the continental masses could not be accepted. It has been firmly established, first by geologists and later by geophysicists, that the rocks beneath the oceans are denser than those in the upper part of the continental crust. The discovery by the seismologists of the Mohorovičić discontinuity (the 'Moho'), where lighter material overlies denser material, has given precision to the picture, and provided a convenient definition of the 'crust' as comprising the rocks above the 'Moho'. The 'Moho' is probably world-wide, and no significant difference has been found in the velocities of shock-waves in the sub-Moho material beneath the oceans and that beneath the eontinents. In two areas in North America, H. E. Tatel, L. H. Adams and M. A. Tuve (Proc. Amer. Phil. Soc., 97, 658-669; 1953) have failed to find the 'Moho', and it may be that in orogenic disturbances some mixing of lower crust and mantle may take place. Although the earlier conception of a continental crust composed of sharply defined horizontal layers of different density is now known to be erroneous, the term 'granitic liayer' is still useful in directing attention to a feature of the continental crust which is absent or only sparingly present in the oceanic areas. 'The oldest rocks known include sediments transported by and laid down in water, which indicates the presence of oceans at the beginning of geological time. The difficulty in finding a satisfactory theory for the ocean-continent relationship may lie in the fact that it was established in pre-geological time and perhaps by processes which have not been operative since. There is evidence that throughout geological time there have been continents and oceans, a crust behaving under stress as it does now, igneous material with the samo variable composition coming up from below, a similar temperature to that of the present, and perhaps life existing throughout. The geologist sees no vestige of a beginning. The remarkable uniformity of crustal conditions and happenings for, say, the past three thousand million years is a fact which must find a place in the speculations of the cosmologist.

Mr. T. Gold discussed the formation and internal development of an earth formed by the agglomeration of solid particles-a model more acceptable to astronomers than the scheme of an originally liquid earth. From a cloud of dust and gas, lumps of solid are formed which aggregate through collision into a large mass bearing the scars of impact, a method of growth fitting the interpretation of the lunar features. In such a model various sources of heat are available - the compression of the interior causing a temperature rise of perhaps $2,000^{\circ}$, the attenuation of seismic waves caused by the impacts, and radioactivity causing a gradual rise of $2,000^{\circ}$ or $3,000^{\circ}$ in three thousand million years. During growth and afterwards, this heating causes a certain amount of melting; everywhere liquid will be mixed with solid long before complete melting could occur. A structure of pores or veins of liquid results, and a transport of liquid depending upon density may occur. The core 
of the earth may have arisen in this way by the downward percolation of dense liquid-molten iron or other substances metallic at the pressures. Lighter liquid penetrating upwards may have supplied the atmosphere, the oceans and the crust. The transport of liquid upwards being prevented by the lower tem. perature of the crust ('thermal blockage'), vulcanism is only possible where there are fractures sufficiently large to alter the thermal structure. Quickly changing stresses resulting from the percolation of liquid from one level to another give rise to earthquakes, a series of shocks rather than single events being the rule. The same type of process is considered responsible for the major deformations of the crust. The internal flow and hydraulic actions to be expected from the model give new freedom for explaining the major problems of earth structure and movement.

Prof. C. E. Tilley commented that, although cosmology is not the province of the geologist, he has a right to express a view as to how matter in the deeper crust and upper mantle is likely to be organized if the earth had passed through the liquid state, and to discuss the implication of Mr. Gold's model. Mr. Gold would have difficulty in explaining the gross layering of the earth's interior without assuming extensive fractional melting. Geologists have been unable to accept the geophysical concept of sharply defined upper and intermediate layers of the crust, and it is reassuring, he said, to have the pronouncement of H. E. Tatel, L. H. Adams and M. A. Tuve that the crust above the 'Moho' in North America may be about as irregular and inhomogeneous as the rocks exposed in the Basement Complex area. In the Canadian Shield, Dr. Lees had estimated thicknesses of at least $200,000 \mathrm{ft}$. involved in tectonic belts-much exceeding the accepted crustal layer of $40 \mathrm{~km}$. - yet the 'Moho' had been found at that depth in Minnesota. 'The 'Moho' could reasonably be associated with a change to ultra-basic material of peridotitic composition. Occurrences of peridotite at St. Paul's Rocks on the mid-Atlantic Ridge, dredged samples of serpentine from south-west of the Azores, and the bastite serpentine 'in place' on the Gettysburg Bank between Gibraltar and the Azores are of significance in ocean areas where the 'Moho' is at a relatively shallow depth. Is it not probable, Prof. 'Tilley asked, that the mylonized peridotite of St. Paul's Rocks is a fragment from beneath the 'Moho' brought up in a great line of fracture ? Recent measurements of heat flow under the oceans have emphasized our lack of knowledge of the radioactivity of oceanic rocks. Petrology and geochemistry, through their recently developed experimental techniques, could contribute in increasing measure to the common problems of geology and geophysics.

Sir Edward Bullard said we cannot at present explain even in principle how the earth has developed to its present state, and that what matters in a synthesis is not whether its details will prove correct but whether it relates the known facts in a way that suggests fresh investigations and experiments. The needs of the petrologists, the measurers of gravity and the seismologists are reconciled in the present accepted picture. The 'granitic layer' of the seismologists can be equated with the 'basement complex' of the Pre-Cambrian and the 'intermediate layer' softened to a gradual and regionaliy variable increase in the proportion of basic rocks with depth. It seems likely that the 'Moho' represents a boundary below which the complications of surface geology do not extend. The 'Moho' must represent a change of material and not a phase change, since the pressures and temperatures concerned are within the range accessible to laboratory experiment, and such a conspicuous change in a common type of rock could scarcely have escaped attention. The behaviour of continental structures at the boundary to the ocean is of eritical importance. Dr. Lees assumed that the structures continued out to sea and that the continental rocks must likewise continue. It seems unlikely, Sir Edward said, that the forces which produced a mountain range on the continent would have stopped short sharply at its edge. It does not follow, however, that the continental rocks continue beyond the edge; the material on which the mountain-building forces act may be different, and continental features usually have no topographic continuation on the floor of the deep sea-as can be seen, for example, from the Hercynian mountains of Europe and the extension of the Appalachians across Newfoundland.

In the open discussion following the four principal contributions, Sir Harold Jeffreys, commenting on a criticism in Dr. Lees's address, said that mathematics is as much a tool as the geologist's hammer or microscope. It tests whether suggested explanations do explain, and it has the property that its methods are always open to inspection. There is no satisfactory ground for believing that the folding measured in mountains is identical with the crustal shortening. Mr. M. W. Strong directed attention to the amount of folding that can be accounted for by local rearrangement of rock masses associated with batholithic intrusions rising and thrusting the sedimentaries aside much in the manner of a salt-plug, but on a vaster scale. Prof. R. M. Shackleton also questioned Dr. Lees's inference of immense crustal compression. Although the oldest visible rocks generally dip at high angles, it does not follow that the crust has suffered general compression. Some of the oldest parts of the crust, for example Southern Rbodesia, show structures primarily due to the rise of granite plutons between which sediments have been sucked down.

Summing up the discussion, Prof. O. T. Jones referred to the view that a continental layer of $35-40 \mathrm{~km}$. could not accommodate in their visibly crumpled form the vast thicknesses of sediments in certain regions, and he pointed out that the effect of one period of diastrophism might have been obliterated before the beginning of the next period of deposition. What remained is a small fraction of that originally laid down and may thus be accommodated without assuming an excessive thickness of crust. It is difficult to arrive at an estimate of the total shrinkage of the earth from the continental areas alone. Mr. Gold's model of a sponge-like interior of rock and metal, he said, does not bear any close relation to any earth with which the geologist is familiar. It does not seem to explain the separation of oceanic and continental areas, nor does it seem to account for the long narrow belts of crumpled strata arising from compression at various times. Although it is said to account for volcanic activity in providing a source of molten material near to the surface at any time, it does not provide an explanation of the long belts along which volcanoes are strung out. The discussion had been of value, however, in the pooling of ideas and in emphasizing the need for new evidence regarding the earth's interior and behaviour and for more accurate data on the properties and materials of the carth's crust. L. HAwkes 